Proceedings

\title{
Assessing the ecological relevance of conservation planning us- ing landscape graph modelling
}

\section{Anissa Bellil 1*}

1 ThéMA, UMR 6049 CNRS/ Université Bourgogne Franche-Comté, Besançon, France

* Correspondence: anissa.bellil@univ-fcomte.fr

\begin{abstract}
:
The connectivity of ecological habitat networks is key for maintaining biodiversity and has therefore been the objective of several conservation policies. In France, the Green and Blue Infrastructure strategy "Trame Verte et Bleue" is dedicated to the protection and management of ecological networks. However, the application of this strategy reveals various spatial patterns considering the diversity of environments and species. Our research aims to compare different forest networks mappings with regards to potential connectivity. This research is based on a generic modelling approach using landscape graphs and develops a way to assess ecological connectivity in conservation planning.
\end{abstract}

Keywords: ecological connectivity, forest networks, landscape graphs, conservation planning

\section{Introduction}

Ecological connectivity is a key factor of population dynamics and is commonly assessed to estimate the contribution of habitat networks to the protection of biodiversity.

Citation: Bellil, A., 2022, Assessing the ecological relevance of conservation planning using landscape graph modelling. SUPTM 2022 conference proceedings sciforum-051191. https://doi.org/10.31428/10317/10481

Publisher's Note: UPCT and Sciforum stays neutral with regard to jurisdictional claims in published maps and institutional affiliations.

Copyright: () 2022 by the authors. Submitted for possible open access publication under the terms and conditions of the Creative Commons Attribution (CC BY) license (https://creativecommons.org/license s/by/4.0/)
Ecological connectivity is increasingly integrated in conservation planning [1-3], but a significant gap is identified in practice [4-6].

In France, the "Trame Verte et Bleue" (TVB) strategy aims to constitute a coherent ecological network, from national to local levels. It is based on the patch-corridor-matrix conceptual model, related to species and their movements [7]. However, the practical application of this strategy goes beyond the boundaries of conservation and planning, combining scientific considerations related to ecology with territorial projects [8]. The distinction between the conceptual ecological network and its operational representation illustrates the difficulty of accounting for connectivity when it comes to action.

Studies on TVB planning showed that ecological connectivity is not properly considered [9]. Indeed, the connectivity concept is misinterpreted and rarely applied at the local level [10]. This study aims to compare different TVB planning maps to characterise their contribution to ecological connectivity by using landscape graphs. These spatial models are relevant tools to estimate the potential connectivity of habitat networks and support decision-making [11,12]. We focused on forest habitat networks of different maps driving from SCoT (French inter-municipal planning instruments). 


\section{Area of study}

Our analysis is based on four SCoT located in the Burgundy Franche-Comté region: Belfort, Grand Autunois Morvan, Grand Nevers, and Grand Avallonnais (Figure 1). The studied SCoT share similar forest cover proportions (between $37 \%$ and $44 \%$ ) but differ for other land cover categories.

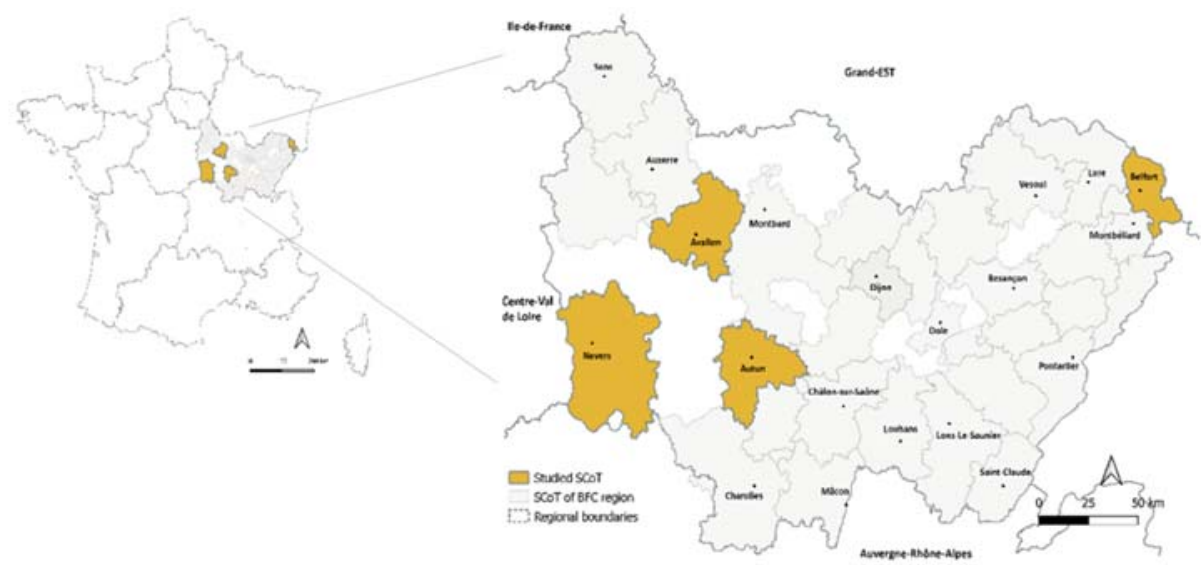

Figure 1. Study area and SCoT

\section{Material and methods}

\subsection{Land cover mapping}

We produced a land cover map by using the following databases: IGN 2018, BD FORET ${ }^{\circledR}$ to map forests; IGN 2018, BD TOPO® to map rivers, wetlands, roads, railways, and urban areas; RPG 2017 for meadows, crops and other open areas; and OSO raster layer 2018 as a base map. The obtained land cover raster map at a resolution of $5 \mathrm{~m}$ is composed of 15 classes.

\subsection{Species selection}

We referred to the typology of Vos and al. [13] to define our forest species from several ecological profiles. We distinguished three main profiles: short dispersal distance with small area requirement, middle dispersal distance with middle area requirement and large dispersal distance with high area requirement.

\subsection{Landscape graph modelling}

A graph is defined as a set of habitat patches (nodes) connected by potential dispersal paths (links). Nodes represent suitable habitats patches [14]. Links represent potential movement paths between habitat patches. From our land cover map, we selected the forested habitat patches with a minimal area of $1 \mathrm{ha}, 10 \mathrm{ha}$, and 100 ha for the first, second, and third ecological profiles respectively. The inter-patch links were weighted by an effective distance computed by assigning to each land cover type a specific resistance value. The resistance value of forest patches was set to 1 and was the minimum.

We created planar graphs linking only neighboring habitats patches. Three graphs are used in relation to the dispersal distances and habitat requirements of the three species profiles. The modelled forest networks correspond to the potential habitats networks.

\section{2}

3 
Connectivity metrics used to characterize connectivity

There are different ways to identify how habitat patches contribute to population dynamics [15,16]. We focused on three metrics defined from three main functions: (1) recruitment, (2) dispersal flux and (3) traversability [17]. The first metric corresponds to the potential recruitment $\mathrm{R}$ or demographic capacity $\mathrm{A}$ of the habitat $\mathrm{i}$. It is intrinsic to every habitat patch and independent of the graph.

The second metric estimates the dispersal flux. It is related to the patch ability to function as a source or receptor independently of its potential recruitment. The metric $\mathrm{F}$ is an indicator of the potential dispersal starting from the habitat $i$ or towards the habitat $i$.

$$
\begin{aligned}
& F_{i}=\sum_{j=1}^{n} A_{j}^{\beta} \mathrm{e}^{-\alpha d \mathrm{i} j} \\
& j \neq \mathrm{i}
\end{aligned}
$$

n: number of habitat patches. $A_{i}$ : habitat capacity. $-\alpha d_{j k}$ : probability of dispersal between patches $i$ and $j$. weighting.

The third metric CF measures the traversability of habitat patches. Based on the electrical circuit theory, it takes into account all possible alternative paths between habitat patch pairs and not only the least cost path to quantify the strength of interaction between each pair of habitats. It thereby makes it possible to estimate their role in relation to the flow.

\subsection{Comparison between modelled forest networks and SCoT forest networks}

We collected forest habitats delimitations from SCoT official institutions in order to perform the comparison. The mapped forest habitats included in SCoT were crossed with the modelled habitats for each ecological profile. Connectivity metrics calculated in modelled habitats were assigned to SCoT habitats when included in the modelled habitats. The metric values inside and outside SCoT habitats were then compared.

\section{Results}

The modelled habitat networks are in accordance with the habitat networks included in the planning documents when considering the capacity and the CF metric, but differences appeared between planning documents in terms of flux metric, as revealed by the metric values inside and outside forest habitats. Some habitats patches with high flux values are located outside the SCoT habitat patches.

In addition, scores metrics differ according to species ecological profiles. Some metrics take higher values inside SCoT habitat patches for large dispersers. Conversely, they tend to be higher outside the habitat patches for small dispersers. Overall, habitat patches corresponding to this profile seem to be less included in SCoT zonings.

Our analysis also reveals critical connectivity areas located outside the SCoT forest networks, although they are important for the dispersal flux of species according to landscape graph models. 


\section{Conclusion and perspectives}

Our generic approach allowed us to compare different planning documents in terms of ecological connectivity response using metrics focusing on area, dispersal and traversability. Disparities were observed between SCoT regarding the dispersal criterion. Connectivity is still widely applied in planning maps, especially when considering different species profiles.

Our approach pointed out differences between SCoT in terms of conservation efforts. It was applied on forest networks but could be reproduced for other TVB sub-frames included in planning documents to analyse connectivity.

Funding: This research received no external funding.

Conflicts of Interest: The author declares no conflict of interest.

\section{References}

1. Hodgson JA, Wallis DW, Krishna R, Cornell SJ. How to manipulate landscapes to improve the potential for range expansion. Methods in Ecology and Evolution [Internet] 2016,7(12):1558-66. Available from: https://besjournals.onlinelibrary.wiley.com/doi/abs/10.1111/2041-210X.12614

2. Albert CH, Rayfield B, Dumitru M, Gonzalez A. Applying network theory to prioritize multispecies habitat networks that are robust to climate and land-use change. Conservation Biology [Internet]. 2017,31(6):1383-96. Available from: https://onlinelibrary.wiley.com/doi/full/10.1111/cobi.12943

3. Balbar AC, Metaxas A. The current application of ecological connectivity in the design of marine protected areas. Global Ecology and Conservation [Internet]. 2019,17:e00569. Available from: https://www.sciencedirect.com/science/article/pii/S2351989418304347

4. Beunen R, Opdam P. When landscape planning becomes landscape governance, what happens to the science? Landscape and Urban Planning [Internet]. 2011,100(4):324-6. Available from: http://www.sciencedirect.com/science/article/pii/S0169204611000557

5. Opdam P. Exploring the role of science in sustainable landscape management. An introduction to the special issue. Sustainability [Internet]. 2018,10(2). Available from: https://library.wur.nl/WebQuery/wurpubs/533682

6. Bormpoudakis D, Tzanopoulos J. The science-practice interface of connectivity in England. Landscape Ecol [Internet]. 2019,Available from: http://link.springer.com/10.1007/s10980-019-00913-9

7. Forman RTT, Godron M. Landscape Ecology. Wiley; 1986. 644 p.

8. Alphandéry P, Fortier A. La trame verte et bleue et ses réseaux : science, acteurs et territoires. vertigo [Internet]. 2012,12(2). Available from: http://www.erudit.org/en/journals/vertigo/2012-v12-n2-vertigo01159/1022543ar/abstract/

9. Avon C, Bergès L, Roche P. Comment analyser la connectivité écologique des trames vertes ? Cas d'étude en région méditerranéenne. Sciences Eaux Territoires [Internet]. 2014, 14(2):14-9. Available from: https://www-cairn-info.inshs.bib.cnrs.fr/revue-sciences-eaux-et-territoires-2014-2-page-14.htm

10. Bergsten A, Zetterberg A. To model the landscape as a network: A practitioner's perspective. Landscape and Urban Planning [Internet]. 2013,119:35-43. Available from: http://www.sciencedirect.com/science/article/pii/S0169204613001254

11. Urban, Minor ES, Schick RS, Treml EA. Graph models of habitat mosaics. Ecology Letters [Internet]. 2009,12(3):260-73. Available from: http://doi.wiley.com/10.1111/j.1461-0248.2008.01271.x

12. Foltête J-C. How ecological networks could benefit from landscape graphs: A response to the paper by Spartaco Gippoliti and Corrado Battisti. 2018

13. Vos CC, Verboom J, Opdam PFM. Toward Ecologically Scaled Landscape Indices. 2001;18.

14. Galpern P, Manseau M, Fall A. Patch-based graphs of landscape connectivity: A guide to construction, analysis and application for conservation. Biological Conservation [Internet]. 2011,144(1):44-55. Available from: http://www.sciencedirect.com/science/article/pii/S0006320710003836

15. Bunn AG, Urban DL, Keitt TH. Landscape connectivity: A conservation application of graph theory. Journal of Environmental Management [Internet]. 2000,59(4):265-78. Available from: https://www.sciencedirect.com/science/article/pii/S0301479700903736

16. Urban D, Keitt T. Landscape Connectivity: A Graph-Theoretic Perspective. Ecology [Internet]. 2001,82(5):1205-18. Available from: https://www.jstor.org.www.sndl1.arn.dz/stable/2679983

17. Foltête J-C, Clauzel C, Vuidel G, Tournant P. Integrating graph-based connectivity metrics into species distribution models. Landscape Ecol [Internet]. 2012,27(4):557-69. Available from: http://link.springer.com/10.1007/s10980-012-9709-4 